\title{
FIXED POINT THEOREMS FOR COMPATIBLE MAPPINGS OF TYPE (R) IN MENGER SPACES
}

\author{
Oinam Budhichandra Singh, Leenthoi N. and Th. Indubala Devi
}

Department of Mathematics Calorx Teachers' University, Ahmedabad-382481, Gujarat, India.

\author{
Keywords: Complete Menger Space, Probabilistic Menger Space, Common fixed point, \\ Compatible mappings of type (R).
}

ABSTRACT The aim of this paper is to introduce the concept of weak compatible mappings of type $(\mathrm{R})$ in menger spaces and to prove a fixed point theorem for compatible mappings of type $(\mathrm{R})$ in menger spaces.

\section{Introduction}

Rohen Singh, M.R \& Shambhu introduced the concept of compatible mappings of type (C) by combinging the definition of compatible mappings and compatible mapping of type $(\mathrm{P})$ and later on it is renamed as compatible mappings of type (R) [14]. Later it is extensively developed by Rohen and many others. In the last decade a number of authors [16], [17], [18] have studied the aspects of compatible mappings of type (R).

The concept of probabilistic metric space were first introduced and studied by Menger [11] which is a generalization of metric spaces. These spaces and their applications were study by Bharuch-Read [1] Chang [4] Ciric [6] Chamola [3] Cain \& Kasriel [2] Debeic and Sarapa [7] Egbert [8] Hadzic [9] and Hicks [10]

Recently Hadzic [9] Radu [13] Cho et al [5] Pathak et al [12] Singh and Pant [19] Spacek [20] Vasuki [21] and many others proved Common fixed point theorems in menger spaces.

Definition 2.1 : A probabilistic metric space is a pair(X,F) where $\mathrm{X}$ is a non-empty set and $\mathrm{F}$ is a mapping from $\mathrm{XxX}$ to $\mathrm{L}$.

For $(\mathrm{u}, \mathrm{v}) \in \mathrm{XxX}$ The distribution function $\mathrm{F}(\mathrm{u}, \mathrm{v})$ is denoted by $\mathrm{Fu}, \mathrm{v}$ the functions $\mathrm{Fu}, \mathrm{v}$ are assumed to satisfy the following conditions.

(P1) $\mathrm{Fu}, \mathrm{v}(\mathrm{x})=1$ for every $\mathrm{x}, \mathrm{o}$ iff $\mathrm{u}=\mathrm{v}$

(P2) $\mathrm{Fu}, \mathrm{v}(\mathrm{o})=\mathrm{o}$ for every $\mathrm{u}, \mathrm{v} \in \mathrm{X}$

(P3) $\mathrm{Fu}, \mathrm{v}(\mathrm{x}) \mathrm{Fv}, \mathrm{u}(\mathrm{x})=\mathrm{Fv}, \mathrm{u}$ for every $\mathrm{u}, \mathrm{v} \in \mathrm{X}$

(P4) if $\mathrm{Fu}, \mathrm{v}(\mathrm{x})=1$ and $\mathrm{F} v, \mathrm{w}(\mathrm{y})=1$

Then $\mathrm{Fu}, \mathrm{w}(\mathrm{x}+\mathrm{y})=1$ for every $\mathrm{u}, \mathrm{v} \mathrm{W} \in \mathrm{X}$

Definition 2.2 A manger. Space is a tripat $(\mathrm{X}, \mathrm{F}, \mathrm{t})$ where $(\mathrm{X}, \mathrm{F})$ is a $\mathrm{PM}-$ Space and $\mathrm{t}$ is $\mathrm{T}$ - norm with the following condition.

(P5)Fu,w (x+y) $\geq t[F u v(x), F v, w(y)]$

For every $\mathrm{u}, \mathrm{v}, \mathrm{w} \in \mathrm{X}$ and $\mathrm{x}, \mathrm{y} \in \mathrm{R}+$

Definition 2.3 : Let $(X, F, t)$ be a Merger space with the continuous T- norm $t$,

(i) A sequence $\left\{p_{n}\right\}$ in $X$ is said to be convergent to a point $P \in X$ if for every $\varepsilon>0$ and $\lambda>0$ there exists an integer $N=N(\varepsilon, \lambda)$ such that $p_{n}=U p(\varepsilon, \lambda)$ for $F p 1 p_{n}(\varepsilon)>L-\lambda$, for all $n \geq N$, we rerate $\mathrm{Pn} \rightarrow \mathrm{P}$ as $\mathrm{n} \rightarrow \infty$ or $\lim _{n \rightarrow \infty} \mathrm{p}_{\mathrm{n}}=\mathrm{p}$

(ii) A sequence $\{\mathrm{pn}\}$ of points in $\mathrm{X}$ is said to be a Cauchy sequence if for every $\varepsilon>0$ and $\lambda>0$ there exists an integer $\mathrm{N}=\mathrm{N}(\varepsilon, \lambda) \geq 0$ such that $\operatorname{Fpnpm}(\varepsilon)>1-\lambda$ for all $\mathrm{m}, \mathrm{n} \geq \mathrm{N}$

(iii) The Merger space $(\mathrm{X}, \mathrm{F}, \mathrm{t})$ is said to be complete if every Cauchy sequence in $\mathrm{X}$ converges to a point in $\mathrm{X}$.

Definition 2.4: Let $(\mathrm{X}, \mathrm{F}, \mathrm{t})$ be a Merger space such that the T-norm is continuous and A,S be mappings from $\mathrm{X}$ into itself. $\mathrm{A}$ and $\mathrm{S}$ are said to be compatible if

$\lim _{n \rightarrow \infty} \operatorname{FSAx}_{\mathrm{n}} \operatorname{SAx}_{\mathrm{n}(\mathrm{x})=1}$

For all $\mathrm{x}>0$ wherever $\{X n\}$ is a sequence in $X$ such that $\lim _{n \rightarrow \infty} A x_{n}=\lim _{n \rightarrow \infty} S x_{n}=z$ 
For some $\mathrm{z} \in \mathrm{X}$.

We introduce the following definitions

Definition 2.5 : Let $(\mathrm{X}, \mathrm{F}, \mathrm{t})$ be a Merger space such that T-norm $\mathrm{t}$ is continuous and $\mathrm{A}, \mathrm{S}$ be mapping from $X$ into itself

$\mathrm{A}$ and $\mathrm{S}$ are said to be compatible of type (R) if

$$
\begin{aligned}
& \lim _{n \rightarrow \infty} F_{A S} x, \operatorname{SAxn}(x)=1 \text { and } \\
& \lim _{n \rightarrow \infty} F_{\text {AA } x n, S S} x n(x)=1
\end{aligned}
$$

For all $x>0$ whenever $\left\{x_{n}\right\}$ is a sequence in $X$ such that $\lim _{n \rightarrow \infty} A x_{n}=\lim _{n \rightarrow \infty} S x_{n}=z$

For some $\mathrm{z} \in \mathrm{X}$.

Definition 2.6: Let $(\mathrm{X}, \mathrm{F}, \mathrm{t})$ be a Merger space such that the T- norm is continuous and A,S be mappings from $\mathrm{X}$ into itself.

$A$ and $\mathrm{S}$ are said to be weak compatible mappings of type $(\mathrm{R})$ if.

$\lim _{n \rightarrow \infty} F_{\mathrm{AA} x \mathrm{n}, \mathrm{SS} x \mathrm{n}(\mathrm{x})} \geq \lim _{\mathrm{n} \rightarrow \infty} \mathrm{F}_{\mathrm{SA} x \mathrm{x}, \mathrm{AS} x \mathrm{n}(\mathrm{x})}$ and $\lim _{\mathrm{n} \rightarrow \infty} \mathrm{F}_{\mathrm{SA} x \mathrm{x}, \mathrm{AS} x \mathrm{n}(\mathrm{x})} \geq \lim _{\mathrm{n} \rightarrow \infty} \mathrm{F}_{\mathrm{SS} x \mathrm{n} \operatorname{AA} x \mathrm{n}(\mathrm{x})}$

For all $\mathrm{x}>0$ whenever $\{\mathrm{xn}\}$ is a sequence in $X$ such that $\lim _{\mathrm{n} \rightarrow \infty} \mathrm{A} x_{\mathrm{n}}=\lim _{\mathrm{n} \rightarrow \infty} \mathrm{S} x_{\mathrm{n}}=\mathrm{z}$ for some $\mathrm{z} \in \mathrm{X}$.

The following proposition 2.7 and 2.8 show that definition 2.4 and 2.5 are equivalent under some conditions.

Proposition 2.7 :Let $(X, F, t)$ be Merger space such that the T-norm is continuous and $t(x, x) \geq x$ for all $\mathrm{x} \in[0,1]$ and let $\mathrm{A}, \mathrm{S}: \rightarrow \mathrm{Xbe}$ continuous mappings. Then $\mathrm{A}$ and $\mathrm{S}$ are compatible of type $(\mathrm{R})$.

Proposition 2.8: Let $(X, F, t)$ be merger space such that the $T$ - norm $t$ is continuous $t(x, x) \geq x$ and for all $\mathrm{x} \in[0,1]$ and let $\mathrm{A}, \mathrm{S}: \mathrm{X} \rightarrow \mathrm{X}$ be compatible mappings of type $(\mathrm{R})$.

If one of $\mathrm{A}$ and $\mathrm{S}$ is continuous, then $\mathrm{A}$ and $\mathrm{S}$ are compatible.

From proposition 2.7 and 2.8 we have

Proposition 2.9 Let $(X, F, t)$ be merger space such that the $T$-norm $t$ is continuous and $t(x, x) \geq x$ for all $\mathrm{x} \in[0,1]$ and let $\mathrm{A}, \mathrm{S}: \mathrm{X} \rightarrow \mathrm{X}$ be compatible mappings. Then $\mathrm{A}$ and $\mathrm{S}$ are compatible if and only if they are compatible of type (R).

The following proposition, show that definition 2.4,2.5 and 2.6 are equivalent under. Some condition but first we have.

Proposition 2.10: Let $(\mathrm{X}, \mathrm{F}, \mathrm{t})$ be a Merger space such that the $\mathrm{T}$ - norm $\mathrm{t}$ is continuous and $\mathrm{t}(\mathrm{x}, \mathrm{x}) \geq \mathrm{x}$ for all $x \in[0,1]$ and let $A, S: X \rightarrow X$ be compatible mappings. Then $A$ and $S$ are weak compatible mappings of type $(\mathrm{R})$ if they are compatible mappings of type $(\mathrm{R})$.

Proposition 2.11 : Let $(X, F, t)$ be a Merger Space such that the $T$-norm $t$ is continuous and $t(x, x) \geq x$ for all $\mathrm{x} \in[0,1]$ and $\mathrm{A}, \mathrm{S}: \mathrm{X} \rightarrow \mathrm{X}$ be continuous mapping $\mathrm{S}$. If $\mathrm{A}$ and $\mathrm{S}$ are weak compatible mappings of type $(\mathrm{R})$, then they are compatible mappings of type $(\mathrm{R})$.

Proposition 2.12: Let $(X, F, t)$ be Merger Space, such that the T-norm $t$ is continuous and $t(x, x) \geq x$ for all $x \in[0,1]$ and $A, S: X \rightarrow X$ be weak compatible of type (R). If one of $A$ and $S$ is continuous, then $\mathrm{A}$ and $\mathrm{S}$ are compatible mappings.

As a direct consequence of proposition 2.7,2.10 and 2.12 we have the following

Proposition 2.13 : Let $(X, F, t)$ be a Merger Space such that T-norm $t$ is continuous and $t(x, x) \geq x$ for all $\mathrm{x} \varepsilon[0,1]$ and $\mathrm{A}, \mathrm{S}: \mathrm{X} \rightarrow \mathrm{X}$ be continuous mappings. Then $\mathrm{A}$ and $\mathrm{S}$ are compatible if and only if they are weak compatible mappings of type (R).

By using proposition 2.10, 2.11 and 2.13 we have the following.

Proposition 2.14: Let $(\mathrm{X}, \mathrm{F}, \mathrm{t})$ be a Merger Space such that the T-norm $\mathrm{t}$ is continuous and $\mathrm{t}(\mathrm{x}, \mathrm{x}) \geq$ $\mathrm{x}$ for all $\mathrm{x} \varepsilon[0,1]$ and $\mathrm{A}, \mathrm{S}: \mathrm{X} \rightarrow \mathrm{X}$ be compatible mappings then of type (R) if and only if they are weak compatible mappings of type $(\mathrm{R})$

i) $\quad \mathrm{A}$ and $\mathrm{S}$ are compatible mappings of type (R) if and only if they are weak compatible mappings of type (R)

ii) $\mathrm{A}$ and $\mathrm{S}$ are compatible mappings if and only if they are weak compatible mappings of type (R).

Next we give two propositions of weak compatible mappings of type (R) on a Merger Space for our main theorem. 
Proposition 2.15: Let $(X, F, t)$ be a Merger Space such that the $T$-norm $t$ is continuous and $t(x, x) \geq$ $\mathrm{x}$ for all $\mathrm{x} \in[0,1]$ and $\mathrm{A}, \mathrm{S}: \mathrm{X} \rightarrow \mathrm{X}$ be mappings of type $(\mathrm{R})$ and $\mathrm{Az}=\mathrm{Sz}$ for some $\mathrm{Z} \in \mathrm{X}$ then $\mathrm{AAz}=\mathrm{ASz}=\mathrm{SA}=\mathrm{SSz}$.

Proposition 2.16: Let $(X, F, t)$ be Merger Space such that the $t$-norm $t$ is continuous and $t(x, x) \geq x$ for all $\mathrm{x} \varepsilon[0,1]$ and A.S $: \mathrm{X} \rightarrow \mathrm{X}$ be mappings. Let $\mathrm{A}$ and $\mathrm{S}$ be weak compatible mappings of type (R) and $\lim _{\mathrm{n} \rightarrow \infty} A \mathrm{x}_{\mathrm{n}}=\lim _{\mathrm{n} \rightarrow \infty} S \mathrm{x}_{\mathrm{n}}=\mathrm{z}$ for some $\mathrm{z} \in \mathrm{X}$

Then we have

(i) $\lim _{n \rightarrow \infty} \mathrm{SAx}_{\mathrm{n}}=\mathrm{Az}$ if $\mathrm{A}$ is continuous

(ii) $\lim _{n \rightarrow \infty} \mathrm{ASx}_{\mathrm{n}}=\mathrm{Sz}$ if $\mathrm{S}$ is continuous

(iii) $\mathrm{ASz}=\mathrm{SAz}$ and $\mathrm{Az}=\mathrm{Az}=\mathrm{Sz}$ if $\mathrm{A}$ and $\mathrm{S}$ are continuous.Lemma 2.17: Let $\left\{\mathrm{x}_{\mathrm{n}}\right\}$ be a sequence in a Merger Space $(X, F, t)$ where $t$ is a continuous $T$-norm and $t(x, x) \geq x$ for all $x \in[0,1]$. If there exist a constant $\mathrm{k} \in(0,1)$ Such that $\mathrm{Fx}_{\mathrm{n}}, \mathrm{x}_{\mathrm{n}+1}(\mathrm{kx}) \geq \mathrm{Fx}_{\mathrm{n}-1}, \mathrm{x}_{\mathrm{n}}(\mathrm{x})$ for all $\mathrm{x}>0$ and $\mathrm{n} \in \mathrm{N}$, then $\left\{\mathrm{x}_{\mathrm{n}}\right\}$ is a Cauchy sequence in $\mathrm{X}$.

\section{Ours main Theorem}

Theorem 3.1.: Let $(X, F, t)$ be a complete Merger Space with $t(x, y) \min (x, y)$ for all $x, y \in[0,1]$ and $\mathrm{P}, \mathrm{Q}, \mathrm{R}, \mathrm{A}, \mathrm{B}, \mathrm{S}, \mathrm{T}$ be mappings from $\mathrm{X}$ itself such that

(3.1) $\mathrm{P}(\mathrm{X}) \cup \mathrm{QAB}(\mathrm{X}) \subset \mathrm{RST}(\mathrm{X})$,

(3.2) The pairs P, QAB and P, RST are weak compatible of type ( R),

(3.3) Q,A,B are continuous,

(3.4) Fz, QABz(x) $\leq \mathrm{Fz}, \mathrm{RSTz}(\mathrm{x})$

(3.5) $\left[\mathrm{F}_{\mathrm{pu}}, \mathrm{Pv}(\mathrm{kx})\right]^{2} \geq \min \left\{\left[\mathrm{F}_{\mathrm{QABu}}, \operatorname{RSTv}(\mathrm{x})\right]^{2},\left[\mathrm{~F}_{\mathrm{QAPu}(\mathrm{x})}, \mathrm{F}_{\mathrm{RSTv}(\mathrm{x}) \mathrm{Pv}}(\mathrm{x})\right.\right.$

$\geq \min \left\{\left[\mathrm{F}_{\mathrm{QABu}}, \operatorname{RSTv}(\mathrm{x})\right]^{2},\left[\mathrm{~F}_{\mathrm{QAPu}(\mathrm{x})}, \mathrm{F}_{\mathrm{RSTv}(\mathrm{x}) \mathrm{Pv}}(\mathrm{x})\right.\right.$

$\mathrm{F}_{\mathrm{QABu}}, \mathrm{RSTv}(\mathrm{x}), \mathrm{F}_{\mathrm{QABu}, \mathrm{Pu}(\mathrm{x})}, \mathrm{F}_{\mathrm{QABu}}, \mathrm{F}_{\mathrm{RSTV}}, \mathrm{Pv}(\mathrm{x})$,

$\mathrm{F}_{\mathrm{QABu}}, \operatorname{RSTv}(2 \mathrm{x}), \mathrm{F}_{\mathrm{QABu}, \mathrm{Pv}(\mathrm{x})}, \mathrm{F}_{\mathrm{QABu}}, \operatorname{RSTv}(\mathrm{x}) \mathrm{F}_{\mathrm{RSTV}}, \mathrm{Pu}(\mathrm{x})$,

$\mathrm{F}_{\mathrm{QABu}}, \mathrm{Pv}(2 \mathrm{x}), \mathrm{F}_{\mathrm{RSTV}}, \mathrm{Pv}(\mathrm{x}), \mathrm{F}_{\mathrm{QABu}} \mathrm{Pu}(\mathrm{x}) \mathrm{F}_{\mathrm{RST}}, \mathrm{Pu}(\mathrm{x})$,

$\left.\mathrm{F}_{\mathrm{QABu}} \mathrm{Pv}(2 \mathrm{x}), \mathrm{F}_{\mathrm{RSTV}}, \mathrm{Pv}(\mathrm{x})\right\}$

For all $u, v, \epsilon, X$ and $x \geq 0$, where $k \in(0,1)$.

Then $\mathrm{P}, \mathrm{Q}, \mathrm{R}, \mathrm{A}, \mathrm{B}, \mathrm{S}$ and $\mathrm{T}$ have a unique common fixed point.

Proof : For any xo $\epsilon \mathrm{X}$, there exist a point $\mathrm{x} 1$, we can choose a point $\mathrm{x} 2$ in $\mathrm{X}$ such that $\mathrm{Px} 0=$ RSTx1. For this point $\mathrm{x} 1$, we can choose a point $\mathrm{x} 2 \epsilon \mathrm{x}$, such that Px1 $=\mathrm{QABx} 2$ and so on, in this manner we can define a sequence $\{\mathrm{yn}\}$ in $\mathrm{X}$ such that

$\mathrm{y}_{2 \mathrm{n}}+\mathrm{RSTx}_{2 \mathrm{n}+1}=\mathrm{Px}_{2 \mathrm{n}}$

$\mathrm{y}_{2 \mathrm{n}+1}=\mathrm{QABx}_{2 \mathrm{n}+2}=\mathrm{Px}_{2 \mathrm{n}+1} \quad \mathrm{n}=0,1,2 \ldots \ldots .$.

Now we shall prove $\mathrm{Fy}_{2 \mathrm{n}}, \mathrm{Y}_{2 \mathrm{n}+1}(\mathrm{kx}) \geq \mathrm{Fy}_{2 \mathrm{n}+1}, \mathrm{Y} 2 \mathrm{n}(\mathrm{x})$, for all $\mathrm{x}>0$, where $\mathrm{k} \in(0,1)$. Suppose that $\mathrm{Fy}_{2 \mathrm{n}}, \mathrm{y}_{2 \mathrm{n}+1}(\mathrm{kx})<\mathrm{Fy}_{2 \mathrm{n}-1}, \mathrm{y}_{2 \mathrm{n}}(\mathrm{x})$. Then by using condition (3.5) and $\mathrm{Fy}_{2 \mathrm{n}}, \mathrm{Y}_{2 \mathrm{n}+1}(\mathrm{kx}) \leq \mathrm{Fy} 2 \mathrm{n}, \mathrm{y}_{2 \mathrm{n}+1}(\mathrm{x})$, we have

$\left[\mathrm{Fy}_{2 \mathrm{n}}, \mathrm{y}_{2 \mathrm{n}+1}(\mathrm{kx})\right]^{2}=\left[\mathrm{FPx}_{2 \mathrm{n}}, \mathrm{Px}_{2 \mathrm{n}}+1(\mathrm{kx})\right]^{2} \geq \min [\mathrm{Fy} 2 \mathrm{n}-1, \mathrm{y} 2 \mathrm{n}(\mathrm{x})]_{2}, \mathrm{Fy} 2 \mathrm{n}-1, \mathrm{y} 2 \mathrm{n}(\mathrm{x}), \mathrm{Fy} 2 \mathrm{n}, \mathrm{y} 2 \mathrm{n}+1(\mathrm{x})$,

Fy2n-1, y2n(x), Fy2n-1, y2n(x), Fy2n-1, y2n(x), Fy2n,y2n+1(x),

Fy2n-1, y2n(x), Fy2n-1, y2n-1(2x), Fy2n-1, y2n(x), Fy2n,y2n(x),

Fy2n-1, y2n+1(2x), Fy2n, y2n(x), Fy2n-1, y2n(x), Fy2n,y2n(x),

Fy2n-1, y2n+1(2x), Fy2n, y2n-1(x)\}

$\geq \min \{[$ Fy2n-1, y2n(x), Fy2n-1, y2n(x), Fy2n, y2n+1(x), [Fy2n-1, y2n(x)]2, Fy2n-1, y2n(x), Fy2n, y2n+1(x),

Fy2n-1, y2n(x), t(Fy2n-1, y2n(x), Fy2n, y2n+1(x),Fy2n-1, y2n(x), t(Fy2n-1, y2n(x), Fy2n, y2n+1(x),

Fy2n-1, y2n(x), t(Fy2n-1, y2n(x), Fy2n, y2n+1(x), Fy2n, y2n+1(x)\}

$\geq \min \{[$ Fy2n, y2n+1(kx)]2, [Fy2n, y2n+1(kx)]2,

$[F y 2 n, y 2 n+1(k x)] 2,[F y 2 n, y 2 n+1(k x)] 2,[F y 2 n, y 2 n+1(k x)] 2$,

Fy2n, y2n+1(kx), Fy2n, y2n+1(kx), Fy2n, y2n+1(kx), [Fy2n, y2n+1(kx)]2 $=[$ Fy2n, y2n+1(kx)]2 
Which is a contradiction. Thus we have Fy2n, y2n+1(kx) $\geq$ Fy2n-1, y2n(x). Similarly we have also Fy2n-1, y2n+1(kx) $\geq$ Fy2n,y2n+1(kx). Therefore, by lemma (2.17), \{yn $\}$ is a Cauchy sequence in $X$. Since the Menger space $(\mathrm{X}, \mathrm{F}, \mathrm{t})$ is complete, $\{\mathrm{yn}\}$ converges to a point $\mathrm{z}$ in $\mathrm{X}$, and the subsequences $\{\mathrm{Px} 2 \mathrm{n}\},\{\mathrm{QABx} 2 \mathrm{n}+1\},\{\mathrm{RSTx} 2 \mathrm{n}+1\}$ and $\{\mathrm{Px} 2 \mathrm{n}\}$ of $\{\mathrm{y} 2 \mathrm{n}\}$ also converges to $\mathrm{z}$.

Now suppose that Q, A, B are continuous, since P and QAB are weak compatible of type (R), it follows from proposition.

PQABx $2 n+1$ and $(\mathrm{QAB})^{2} \mathrm{x} 2 \mathrm{n}+1 \rightarrow(\mathrm{QAB}) \mathrm{z}$, as $\mathrm{n} \rightarrow \infty$.

Now putting $\mathrm{u}=(\mathrm{QAB}) \mathrm{x} 2 \mathrm{n}+1$ and $\mathrm{v}=\mathrm{x} 2 \mathrm{n}+1$ in condition (3.5), we have

$\left[\mathrm{F}_{\mathrm{P}(\mathrm{QAB}) \mathrm{x}_{2 \mathrm{n}+1}}, \mathrm{Px}_{2 \mathrm{n}+1}(\mathrm{kx})\right]^{2} \geq \min \left[\mathrm{F}_{(\mathrm{QAB}) 2_{\mathrm{x}_{2 n+1}}}(\mathrm{RST}) \mathrm{x}_{2 \mathrm{n}+1}(\mathrm{x})\right]^{2}$

$\mathrm{F}_{(\mathrm{QAB}) 2_{\mathrm{x}_{2 n+1}}}, \mathrm{P}(\mathrm{QAB}) \mathrm{x}_{2 \mathrm{n}+1}(\mathrm{x}), \mathrm{F}_{(\mathrm{RST}) \mathrm{x}_{2 \mathrm{n}+1}}, \mathrm{Px}_{2 \mathrm{n}+1}(\mathrm{x})$,

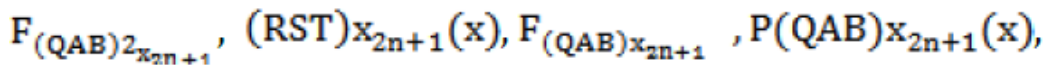

$\mathrm{F}_{(\mathrm{QAB}) 2_{\mathrm{x}_{2 n+1}}}(\mathrm{RST}) \mathrm{x}_{2 \mathrm{n}+1}(\mathrm{x}), \mathrm{F}_{(\mathrm{RST}) \mathrm{x}_{2 \mathrm{n}+1}}, \mathrm{Px}_{2 \mathrm{n}+1}(\mathrm{x})$,

$\mathrm{F}_{(\mathrm{QAB}) 2_{\mathrm{x}_{2 n+1}}},(\mathrm{RST}) \mathrm{x}_{2 \mathrm{n}+1}(\mathrm{x}), \mathrm{F}_{(\mathrm{QAB}) 2_{\mathrm{x}_{2 n+1}}}, \mathrm{Px}_{2 \mathrm{n}+1}(\mathrm{x})$,

$\mathrm{F}_{(\mathrm{QAB}) 2_{\mathrm{x}_{2 n+1}}},(\mathrm{RST}) \mathrm{x}_{2 \mathrm{n}+1}(\mathrm{x}), \mathrm{F}_{(\mathrm{RST}) \mathrm{x}_{2 \mathrm{n}+1}}, \mathrm{P}(\mathrm{QAB}) \mathrm{x}_{2 \mathrm{n}+1}(\mathrm{x})$,

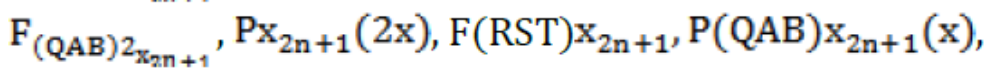

$\mathrm{F}_{(\mathrm{QAB}) 2_{\mathrm{x}_{2 n+1}}}, \mathrm{P}(\mathrm{QAB}) \mathrm{x}_{2 \mathrm{n}+1}(\mathrm{x}), \mathrm{F}_{(\mathrm{RST}) \mathrm{x}_{2 \mathrm{n}+1}}, \mathrm{P}(\mathrm{QAB}) \mathrm{x}_{2 \mathrm{n}+1}(\mathrm{x})$,

$\mathrm{F}_{(\mathrm{QAB}) 2_{\mathrm{x}_{2 n+1}}}, \mathrm{Px}_{2 \mathrm{n}+1}(2 \mathrm{x}), \mathrm{F}_{(\mathrm{RST}) \mathrm{x}_{2 \mathrm{n}+1}}, \mathrm{Px}_{2 \mathrm{n}+1}(\mathrm{x})$,

Letting $\mathrm{n} \rightarrow \infty$ we have $=\left[\mathrm{F}_{(\mathrm{QAB}) \mathrm{z}, \mathrm{z}(\mathrm{x})}\right]$

Which is a contradiction. Therefore we have $(\mathrm{QAB}) \mathrm{z}=\mathrm{z}$. Since $\mathrm{P}(\mathrm{x}) \subset \mathrm{RST}(\mathrm{x})$,

By using condition (3.4) we have $\mathrm{F}_{\mathrm{z}, \mathrm{RSTz}(\mathrm{x})} \leq \mathrm{F}_{\mathrm{z}, \mathrm{QABz}(\mathrm{x})}$

Which implies that $\mathrm{RSTz}=\mathrm{z}$ because $\mathrm{QABz}=\mathrm{z}$.

Again put $u=Q A B x_{2 n+1}$ and $v=z$ in condition (3.5), we have

$\left[\mathrm{F}_{\mathrm{P}(\mathrm{QAB}) \mathrm{x}_{2 \mathrm{n}+1}}, \mathrm{P}_{\mathrm{z}}(\mathrm{kx})\right]^{2} \geq \min \left[\mathrm{F}_{(\mathrm{QAB}) 2_{\mathrm{x}_{2 n+1}}}, \mathrm{RSTz}_{(\mathrm{x})}\right]^{2}$

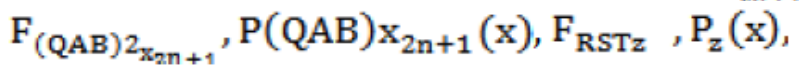

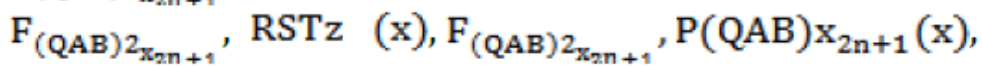

$\mathrm{F}_{(\mathrm{QAB}) 2_{\mathrm{x}_{2 n+1}}}, \operatorname{RSTz}(\mathrm{x}), \mathrm{F}_{\mathrm{RSTz}}, \mathrm{P}_{\mathrm{z}}(\mathrm{x})$,

$\mathrm{F}_{(\mathrm{QAB}) 2_{\mathrm{x}_{2 n+1}}}, \operatorname{RSTz}(\mathrm{x}), \mathrm{F}_{(\mathrm{QAB}) 2_{\mathrm{x}_{2 n+1}}}, \mathrm{P}_{\mathrm{z}}(2 \mathrm{x})$,

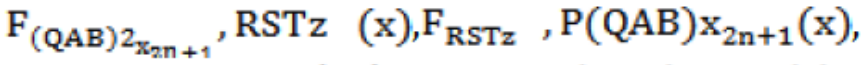

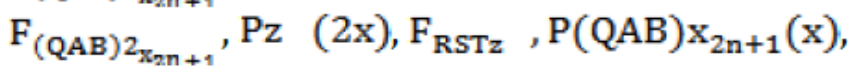

$F_{(Q A B) 2_{x_{2 n+1}}}, P(Q A B) x_{2 n+1}(x), F_{R S T z}, P(Q A B) x_{2 n+1}(x)$,

$\mathrm{F}_{(\mathrm{QAB}) 2_{\mathrm{x}_{2 n+1}}}, \mathrm{Pz}(2 \mathrm{x}), \mathrm{F}_{\mathrm{RSTz}}, \mathrm{Pz}$ (x),

By taking limit $\mathrm{n} \rightarrow \infty$, we have $=\left\{\mathrm{F}_{\mathrm{z}, \mathrm{Pz}(\mathrm{x})}\right\} 2$

Which is a contradiction, therefore $\mathrm{Pz}=\mathrm{z}$. Now we show that $\mathrm{Az}=\mathrm{z}$ infact by condition (3.5), and by putting $\mathrm{u}=\mathrm{Az}$ and $\mathrm{v}=\mathrm{z}$, we have

$\left[\mathrm{F}_{\mathrm{P}(\mathrm{A}) \mathrm{z}, \mathrm{Pz}(\mathrm{kx})}\right]^{2} \geq \min \left[\left\{\mathrm{F}_{(\mathrm{QAB}) \mathrm{Az}, \mathrm{RSTz}(\mathrm{x})}\right\}^{2}\right.$,

$F_{(Q A B) A z, P(A) z(x)}, F_{R S T z, P(A) z(x) \text {, }}$

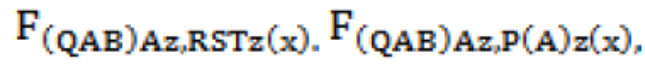

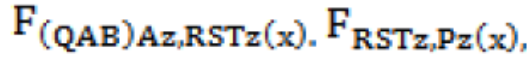

$F_{(Q A B) A z, R S T z}(x) . F_{(Q A B) A z, P z}(2 x)$,

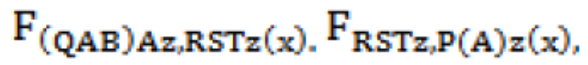

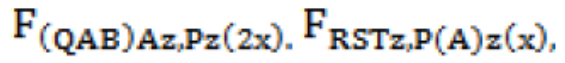

$F_{(Q A B) A z, P(A) z(x) .} F_{R S T z, P(A) z(x)}$,

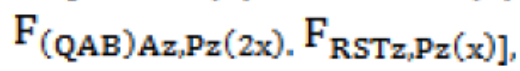

$=\left\{\mathrm{F}_{\mathrm{Az}, \mathrm{z}(\mathrm{x})}\right\}^{2}$ 
Which is a contradiction, therefore $\mathrm{Az}=\mathrm{z}$. Similarly, if e put $\mathrm{u}=\mathrm{Bz}$ and $\mathrm{v}=\mathrm{z}$, we obtain $\mathrm{Bz}=\mathrm{z}$ and, if we put $\mathrm{u}=\mathrm{Qz}$ and $\mathrm{v}=\mathrm{z}$ we have $\mathrm{Qz}=\mathrm{z}$.

Similarly, we can show that $\mathrm{Rs}=\mathrm{z}, \mathrm{Sz}=\mathrm{z}$ and $\mathrm{Tz}=\mathrm{z}$.

Therefore combining above results, we have $\mathrm{Pz}=\mathrm{Az}=\mathrm{Bz}=\mathrm{Qz}=\mathrm{Rz}=\mathrm{Sz}=\mathrm{Tz}=\mathrm{z}$, Hence $\mathrm{z}$ is a common fixed point of $\mathrm{P}, \mathrm{A}, \mathrm{B}, \mathrm{Q}, \mathrm{R}, \mathrm{S}$ and $\mathrm{T}$.

It follows easily from (3.5) that $\mathrm{z}$ is a unique common fixed point of $\mathrm{P}, \mathrm{A}, \mathrm{B}, \mathrm{Q}, \mathrm{R}, \mathrm{S}$ and $\mathrm{T}$.

Theorem 3.2 : Let P,A,B,Q,R,S and T be mappings from a complete metric space $(\mathrm{x}, \mathrm{d})$ into itself such that

(3.2.1) $\mathrm{P}(\mathrm{X}) \subset \mathrm{RST}(\mathrm{X})$ and $\mathrm{P}(\mathrm{X}) \subset \mathrm{QAB}(\mathrm{X})$,

(3.2.2) $\mathrm{Q}, \mathrm{A}, \mathrm{B}$ are continuous,

(3.2.3) the pairs $\{\mathrm{P}, \mathrm{QAB}\}$ and $\{\mathrm{P}, \mathrm{RST}\}$ are weakly compatible of type $(R)$

(3.2.4) $\mathrm{PA}=\mathrm{AP}, \mathrm{PB}=\mathrm{BP}, \mathrm{PS}=\mathrm{SP}$, $\mathrm{PQ}=\mathrm{QP}$,

(3.2.5) d $\{x, Q A B x(x)\} \geq d\{x, \operatorname{RSTx}(x)\}$,

(3.2.6) $d 2(P x, P y) \leq k . \max \{d 2(Q A B x, R S T y) . d(Q A B x, P x) . d(R S T y, P y)$

d(QABx,RSTy).d (QABx,Px),d(QABx,RSTy).d (RSTy, Py),

$1 / 2 \mathrm{~d}(\mathrm{QABx}, \mathrm{RSTy}) . \mathrm{d}(\mathrm{QABx}, \mathrm{Py}), \mathrm{d}(\mathrm{QAB}, \mathrm{RSTy}) . \mathrm{d}(\mathrm{RSTy}, \mathrm{Px})$,

$1 / 2 \mathrm{~d}(\mathrm{QAB} x, \mathrm{Py}) \cdot \mathrm{d}$ (RSTy,Px),d(QABx,RSTx). d (RSTy, Px),

$1 / 2 \mathrm{~d}(\mathrm{QABx}, \mathrm{Py}) \cdot \mathrm{d}(\mathrm{RSTy}, \mathrm{Py})$

For all $\mathrm{x}, \mathrm{y}$ in $\mathrm{X}$, where $\mathrm{k} \in(0,1)$. Then $\mathrm{P}, \mathrm{Q}, \mathrm{A}, \mathrm{B}, \mathrm{R}, \mathrm{S}$ And $\mathrm{T}$ have $\mathrm{A}$ unique common fixed point in $\mathrm{x}$.

Theorem 3.2 can be proved in similar manner as Theorem 3.1.

\section{References}

[1] Bhuruch-Read, A.T.: Fixed point theorem in probabilistic analysis, Bull. Amer. Math. Soc. 82(1976), 641-657.

[2] Cain, G.L. and Kasriel, R.H.: Fixed and periodic points of local contraction mappings on PMspace, Math. Sytem Theory 9(1976), 289-297.

[3] Chamola, K.P.: Fixed points of mappings satisfying a new contraction condition in random normed space, Math. Japonica 33(1988), 821-825.

[4] Chang, S.S.: On some fixed point theorems in PM-space and its Application, Z. Wahrsch. Verw. Gebiete 63(1983), 463-474.

[5] Cho, Y.J., Murthy, P.P. and stojakovic, M. : Compatible mappings of type ( and common fixed points in Menger spac, Comm. Of Korean Math. J. 7(1992), 325-339.

[6] Ciric, L.B.: On fixed point of generalized contractions on probabilistic metricspace, Publ. Inst. Math. Beograd. 18(1975), 71-78.

[7] Debeic, R. and Sarapa, N. : A coomon fixed point theorem for three mappings on menger space, math. Japonica 34(1989), 919-923.

[8] Egbert, R.J.: products and quotients of probabilistic metric space, Pacific J. Math. 24(1968), 437-455.

[9] Hadzic, O.: A fixed point theorem in Menger space, Publ. Inst. Math. Beograd 20(1979),107112.

[10]Hicks, T.J.: Fixed point theory in probabilistic metric spaces, Review of Research, fac. Sci. Math. Series, Univ. of Novi. Sad, 14(1983), 63-72.

[11]Menger, K.: Statistical metric, Proc. Nat. Acad. Sci. U.S.A. 28 (1942), 14-17.

[12]Pathak, H.K. Kang, S.M. and Baek, J.H. : Weak compatible mappings type (A) and common fixed points in Menger spaces, Comm. Korean Math. Soc. 10(1995) No.1, PP. 67-83. 
[13]Radu, V.: On some contraction type mappings in Menger spaces, An Univ. Timisora, Stiinte Math.. 23(1995), 61-65.

[14]Rohen Y., Singh, M.R. and Shambhu L., Common fixed point of compatible mapping of type (C) in Banach spaces, Proc. Math. Soc. BHU,20(2004),77-87.

[15]Rohen Y. Fixed point theorems of compatible mappings of type (R) in metric spaces, Int. J. Open problems Compt. Math. Vol.3, No.5 Dec., 2010.

[16]Rohen Y. M. Krishnando and L. Shambhu, Common fixed point theorems of compatible mappings of type (R)IJMSEA, 6(I) (Jan,2012), 355-361.

[17]Rohen Y.,M. Koireng Meitei and Leenthoi Ningombam Common fixed point of compatible mappings of type (R) General Mathematics Notes.

[18]Rohen Y. and Singh M.R. Common fixed points of compatible mappings of type (R) in complete metric spaces IJMSEA. 2(IV)(2008) 295-303.

[19] Singh S.L. and Pant, B.D. : Coincidence and fixed point theorems for a family of mappings on Menger space and Extension of Uniform spaces, Math. Japonica 33(1988), 957-973.

[20] Spacek, A.: Note On K. Menger's Probabilistic geometry, Czechosvak Math. J. 6(1956), 72-74.

[21] Vasuki, R.: A fixed point theorem for a sequence of maps satisfying a new contraction type condition in Menger space, Math. Japonica 36 (1990), 1099-1102. 